\title{
Elitismo e representação utilitarista em John Stuart Mill: o ensaio Sobre a Liberdade e sua transposição na forma de governo ideal
}

\author{
Alisson Ortiz Rigitano ${ }^{1}$ \\ Universidade de São Paulo \\ rigitano@usp.br
} Como citar este artigo: Rigitano, Alisson Ortiz. "Elitismo e representação utilitarista em John Stuart Mill: o ensaio
Sobre a Liberdade e sua transposição na forma de governo ideal", Intelligere, Revista de História Intelectual, n¹1, pp. 198-
218. 2021. Disponível em <http://revistas.usp.br/revistaintelligere>. Acesso em dd/mm/aaaa-

Resumo: Este manuscrito analisa duas obras de John Stuart Mill em busca de entrecruzamentos valiosos às suas respectivas interpretações: o ensaio Sobre a Liberdade, de 1859, e Considerações sobre o Governo Representativo, de 1862. Trata-se de investigar quais são os fundamentos da concepção de liberdade de Mill a fim de verificar por que implicam idealmente na escolha do governo representativo e, principalmente, por que a representação é uma condição para a realização de sua concepção particular de liberdade. Ao explorar as correspondências entre as duas obras, pretende-se avançar na problematização das raízes dos valores democráticos liberais.

Palavras-chave: John Stuart Mill. Democracia Liberal. Governo Representativo.

\section{Elitism and utilitarian representation in John Stuart Mill: the essay On Liberty and its transposition into the ideal form of government}

Abstract: This manuscript examines two works of John Stuart: the essay On Liberty (1859) and Considerations on Representative Government the (1862). We tried to answer why the representation is a condition for the realization of his particular conception of freedom and, by exploring the correspondences between the two works, we intend to advance in the problematization of the roots of liberal democratic values.

1 Alisson Ortiz Rigitano é Economista de formação e mestre em Economia (Universidade Estadual de Londrina/UEL). Atualmente desenvolve pesquisa de doutorado em História Econômica na Universidade de São Paulo (USP), com pesquisa concentrada em história do pensamento econômico. OrCID: https://orcid.org/0000-0002-4512-6059 
Keywords: John Stuart Mill. Liberal Democracy. Representative Government.

\section{Introdução}

Olhar sob perspectiva a obra completa de um autor como John Stuart Mill, com alguma abrangência e ao mesmo tempo profundidade, é uma tarefa que pode, justificadamente, durar bastante tempo. Trata-se de alguém que escreveu sobre Lógica, Epistemologia, Economia, Filosofia Social e Política, Ética, Metafísica, Religião, além de muitos assuntos de importância pública em sua época ${ }^{2}$. Apesar de seu pensamento se entrecruzar em torno de alguns pressupostos ou ideias fundamentais, sobretudo em sua visão determinística de mundo, centrada no progresso moral e no desenvolvimento individual, qualquer delimitação de seu pensamento incorreria certamente no enquadramento disciplinar de um autor que transborda qualquer limite concebível para as práticas científicas comuns na atualidade. Não é à atoa que é considerado um clássico na história do Pensamento Econômico ao mesmo tempo em que é ainda mais relevante em outros campos do saber, como a Ciência Política ${ }^{3}$.

Ainda que Mill tenha reinado no mundo das ideias inglês por certo período - e por isso sua obra mereça ser estudada pela relevância e influência históricas -, aprender mais sobre suas reflexões significa uma possibilidade de avanço na compreensão da realidade contemporânea, sobretudo no que tange à análise discursiva de argumentos em torno de assuntos como democracia, governo e sociedade. Trata-se da chave para compreender o "ABC" do

${ }^{2}$ Cf. Heydt $(2011 ; 2015)$ sobre perspectivas gerais a respeito da vida e obra do autor.

3 Sobre à contribuição de Mill na história do Pensamento Econômico, além dos "Princípios" (Mill, [1848], 1996), cf., por exemplo, Heilbroner (1996), Roll (1972) e Dennis (1978). Em todos os três não é dedicado um capítulo inteiro à Mill, como é feito com diversos outros autores, os quais se tornaram mais emblemáticos na história das doutrinas econômicas, como Smith, Ricardo, Marshall e Keynes - para se citar somente alguns dos famosos economistas ingleses e que também, de uma forma ou de outra, são alinhados aos princípios liberais e à discussão dos limites e critérios para intervenção do Estado no Mercado. Certamente todos esses "economistas clássicos", ora citados, possuem obras que se desviam das questões propriamente econômicas, no entanto, podemos dizer que Mill é o que mais frequentemente é reconhecido em outros campos do saber; Marx, por exemplo, em O capital, dedica-se a polemizar, muitas vezes com certo sarcasmo, o pensamento milliano ou o que ele representa. Sobre a análise de Marx sobre os autores do início da economia política até sua época, cf., a versão em português de Teorias da Mais Valia (1985) - conhecido como Livro 4 de O capital ou na edição francesa (MARX, 1974). 
liberalismo, ou seja, os fundamentos do pensamento liberal e seus valores democráticos ${ }^{4}$.

Em termos de porte e factibilidade, cobe aqui fazer uma leitura dos argumentos millianos sobre a delimitação do espaço de autonomia e liberdade individuais, isto é, os limites para a intervenção dos indivíduos uns sobre os outros, em particular ou coletivamente - e para isso, a principal obra de referência num primeiro tópico será seu ensaio Sobre a Liberdade, publicado em 1959.

Valendo-se dessa leitura, em seguida buscou-se compreender como sua concepção de liberdade desemboca na forma de governo ideal em seu livro Considerações sobre o governo representativo, de 1861. Trata-se, portanto, de investigar quais os fundamentos da concepção de liberdade de Mill, a fim de verificar por que implicam idealmente na escolha do governo representativo e quais fundamentos e determinações da representação são condições para a realização de sua concepção de liberdade. Em suma, como se dá a transposição da liberdade milliana para as instituições governamentais.

\section{O ensaio Sobre a Liberdade}

Como é bem sabido, John Stuart Mill (1806 - 1873), filho de James Mill (1773 - 1836), preceptorado por Jeremy Bentham (1748 - 1832), foi nutrido em uma educação programática e erudita desde a mais tenra infância, porém, após uma espécie de colapso emocional ${ }^{5}$, viu-se impelido a repensar e a desenvolver sistematicamente grande parte dos temas que lhe eram relevantes.

Seu livro Princípios de Economia, por exemplo, foi o tratado de referência na economia política inglesa por algumas décadas e contém diversas reflexões que podem ser exemplificativas pela sua forma peculiar de encarar o progresso humano. Já Utilitarismo (1861) apresenta sua formulação "relativa"

\footnotetext{
${ }^{4}$ Vale-se aqui das palavras de Bobbio (2000), notório e tradicional cientista político, para quem "o ensaio de Mill é o ABC do liberalismo. Mas após estas letras, como ocorreu nos últimos cento e cinquenta anos, vêm todas as demais letras do alfabeto. E não chegamos ainda ao Z." (BOBBIO, 2000, p. 111). Para o autor, as principais insatisfações com a ideia de democracia nas sociedades contemporâneas se devem, sobretudo, ao não cumprimento de suas promessas teóricas. Análises antagônicas ao diagnóstico de Bobbio sobre a democracia, podemos encontrar em Wood (2003), Machperson (1978) e Offe (1984). Um exame detalhado dos diversos conceitos relacionados à ideia de democracia, dentro da chave considerada liberal, consta em Sartori (1987).

${ }^{5} \mathrm{O}$ autor define o período que antecede uma verdadeira virada em seu pensamento como "crise mental" (MILL, [1873], 1981).
} 
da felicidade do maior número e se tornou a obra mais emblemática da tradição utilitarista ${ }^{6}$. Mas foi em seu Ensaio sobre a Liberdade que Mill conseguiu penetrar em nossos dias com mais amplitude, atualidade e relevância.

O manuscrito trata da "natureza e os limites do poder que pode ser exercido legitimamente pela sociedade sobre o indivíduo" (MILL, [1859], 2010, p. 37) e tem como objetivo, nas palavras do autor:

[...] afirmar um princípio básico muito simples, o modo correto para ordenar de forma absoluta as relações da sociedade para com o indivíduo, seja por meio de compulsão e controle, seja por meio de força física na forma de sanções penais, seja ainda pela coerção moral da opinião pública. Esse princípio diz que o único objetivo pelo qual a humanidade pode, de forma individual ou coletiva, interferir com a liberdade de ação de qualquer de seus membros, é a proteção dela própria. E que o único propósito pelo qual o poder pode ser constantemente exercido sobre qualquer membro de uma comunidade, contra a vontade deste, é o de prevenir danos para os outros membros (MILL, [1859], 2010, p. 49).

Portanto, na base dessa argumentação está a preocupação segundo a qual uma sociedade, ainda que livre, pode exercer, a chamada "tirania da maioria" " . O autor parte do dilema situado na possibilidade de o poder ser exercido pelo conjunto da sociedade, ainda que por meio de mecanismos democráticos, de maneira incisiva e abrangente o suficiente para diminuir o raio de liberdade individual, tão ou mais intensamente quanto no estado autoritário.

Não se trata apenas de uma preocupação com o monopólio da maioria no exercício do poder político sobre si e sobre potenciais minorias. A preocupação é situada também nas formas de tirania social que advém da tirania política. Isso ocorre porque as ordens políticas da maioria, para além de

\footnotetext{
${ }^{6}$ A influência de Mill se deve à sua reflexão alternativa, em que admite a impossibilidade de mensuração objetiva do bem-estar coletivo, sendo mais importante a qualificação da qualidade e relevância na realização do progresso humano. Ari Tank Brito, que escreve o prefácio e tradução da versão analisada, diz que "um filósofo utilitarista que descobre que o utilitarismo, mesmo que funcionando, não o deixaria feliz, certamente tem um grande problema nas mãos". A solução de Mill, de maneira bastante simplista e reducionista, é ilustrada pela sua frase célebre "melhor ser um Sócrates insatisfeito que um tolo satisfeito" (Mill, [1961], 2006, p. 110). ${ }^{7}$ Esse termo ganhou evidência depois de Tocqueville ([1835], 2005), que dedica um capítulo para o assunto iniciando com os dizeres: "Considero ímpia e detestável a máxima de que, em matéria de governo, a maioria do povo tem o direito de fazer tudo; apesar disso situo na vontade da maioria à origem de todos os poderes. Estarei em contradição comigo mesmo?” (TOCQUEVILLE, [1835], 2005, p. 294).
} 
sua execução, advêm de um corpo social formado principalmente por opiniões, as quais extrapolam o campo político e podem penetrar com frequência nos detalhes da vida dos indivíduos. Há que se ater, nas palavras de Mill, à "necessidade de proteção também contra a tirania de opiniões, contra a tendência da sociedade em impor, por meios diversos que as penas civis, suas próprias ideias e práticas como regras de conduta para aqueles que discordam delas” (MILL, [1859], 2010, p. 43).

O autor afirma que "tudo o que faz a existência ter valor para alguém depende da imposição de restrições às ações das outras pessoas" (MILL, [1859], 2010, p. 43), por isso, a questão que mais lhe interessa é a produção de regras adequadas para atingir o melhor equilíbrio entre independência individual e controle social. Para ele, essa questão passa grande parte da experiência social despercebida, porquanto a percepção humana do que é certo ou errado, louvável ou criticável é influenciada por muitos motivos alheios à razão, os mesmos que afetam suas preferências, seu gosto, em suma, os sentimentos de cada pessoa sobre a conduta dos outros é que são determinantes dos seus julgamentos.

Restaria em aberto, então, um princípio pelo qual a "impropriedade ou não de uma interferência" seja testada; na ausência desse princípio ou de uma regra geral, "a interferência do governo é com igual frequência impropriamente invocada e impropriamente condenada" (MILL, [1859], 2010, p. 49). Nesse aspecto, sua argumentação é centrada em como ordenar as relações do indivíduo com a sociedade. Para ele, a coação, uma vez que a humanidade seja capaz de se guiar pela convicção e pela persuasão ${ }^{8}$, passa a ser justificável apenas para a segurança das pessoas. De resto, o verdadeiro tribunal para reger os direitos abstratos do homem deve ser a utilidade. Em suas palavras:

\footnotetext{
${ }^{8}$ Mill se refere à essa capacidade como uma determinante do estágio de avanço da civilização pois, segundo ele, essa doutrina só se aplica em seres humanos que estejam na maturidade de suas faculdades. Em Mattos (2008), é analisado como Mill diferencia sociedades "civilizadas" e sociedades "atrasadas", e a consequência dessa característica no papel do estado. De acordo sua essa análise, ele considera os povos "civilizados" muito superiores aos "atrasados" em questões como qualidades morais, intelectuais e estéticas, não associando, no entanto, a questões de cunho racial, como aquelas ligadas às diferenças naturais. Ainda sobre essa questão, Levkovych (2010) analisa a influência da questão colonialista nas ideias de Mill e como o autor resolve o problema das identidades coletivas, tratando-as como mero acaso da soma de individualidades, pelo que se justificam as investidas colonialistas pelo bem do desenvolvimento da humanidade.
} 
Vejo a utilidade como o tribunal final em todas as questões éticas, mas ela deve ser utilidade em seu sentido mais amplo, firmada nos interesses do homem enquanto um ser que progride. Esses interesses, afirmo, autorizam a sujeição da espontaneidade individual ao controle externo somente em relação às ações de cada pessoa que concernem aos interesses dos outros (MILL, [1859], 2010, p. 51).

Dessa concepção advém o que Mill chamou de "o lugar apropriado da liberdade", ou seja, aquela porção da vida de uma pessoa que só afeta ela mesma, e se afeta outras só o faz indiretamente ou com o livre consentimento delas. Compreendem-se resumidamente três dimensões: o domínio da consciência (1), a liberdade de gosto e inclinações (2) e a combinação entre indivíduos (3).

O domínio da consciência implica, quase como corolário, na liberdade tanto de pensamento como de discussão. Para Mill:

[...] se a humanidade, exceto uma pessoa, tivesse uma opinião, e
essa pessoa tivesse uma opinião contrária, a humanidade não teria
mais justificativa para silenciá-la do que ela para silenciar a
humanidade. [...] Mas o prejuízo característico de silenciar a
expressão de uma opinião reside no fato de que isto é roubar a
raça humana, tanto a posteridade quanto a geração atual, tanto
aqueles que discordam da opinião quanto aqueles que a
sustentam, e esses ainda mais que os primeiros. Pois, se a opinião
está certa, eles são privados da oportunidade de trocar o erro pela
verdade e, se ela está errada, eles perdem a percepção mais clara e
vívida da verdade, produzida pela colisão desta com o erro, um
benefício tão grande quanto o primeiro (MILL, [1859], 2010, p.
58).

Mill se detém aos benefícios objetivos da formulação e expressão de opiniões e sobre os prejuízos de silenciá-las, não só para a geração presente mas para toda a humanidade. Tais prejuízos são categorizados pelo autor conforme as hipóteses de as opiniões serem falsas ou verdadeiras. No caso em que determinada opinião possa ser falsa, sua sujeição ao silêncio é uma presunção de que a opinião oposta seja infalível, ou seja, que não possa existir outra opinião mais aproximada da verdade. Mas as opiniões, para que possam ser admitidas como verdades, principalmente para finalidades de ação, devem se submeter à liberdade de contradição e refutação.

Há que se admitir, portanto, que as crenças são úteis mesmo que contrárias à verdade, primeiro porque não é possível saber se uma opinião é verdadeira ou falsa e, segundo, porque silenciar uma discussão é um mal em si, independentemente. Ainda que seja possível admitir que uma crença contenha 
toda a verdade, se não puder ser contestada, passa a ser sustentada apenas como um dogma ou um preconceito, e mais do que isso, perde a possibilidade de se conhecer ainda mais sobre seus detalhes, perdendo também a vivacidade. Admite também o valor de uma terceira possibilidade, talvez a principal delas, que seria o complemento, a relativização ou a convergência das opiniões, as quais, apesar de conflitantes, podem compartilhar da verdade entre si.

Para muito além desse benefício da diversidade de opiniões - advindo das opiniões que concorrem para que a humanidade avance em direção ao desenvolvimento de seu potencial moral e intelectual -, a liberdade tratada por Mill - de gosto e inclinações, de discussão e propagação de convicções implica e é implicada por uma das principais formas de bem-estar humano: a individualidade. Por isso, aos homens deve ser permitido agir de acordo com suas opiniões, por sua conta e risco, desde que não venham a ferir a liberdade de seus semelhantes. Em suas palavras, "assim como é útil que enquanto a humanidade for imperfeita haja diferentes opiniões, assim devem ser também as experiências de vida" (MILL, [1859], 2010, p. 114), e pelas mesmas razões, desde que sejam admitidos os riscos de prejuízo próprio e não seja apresentado nenhum dano potencial a outrem.

Há de se reconhecer, portanto, o valor intrínseco da espontaneidade individual e o fato de a maioria das pessoas, apesar de não negar algum valor aos aspectos ligados às qualidades dos indivíduos, não estar minimamente disposta a aceitar a maturidade e o domínio próprio como determinantes da capacidade de interpretar a vida e fazer juízo dos valores e costumes. Mas, de acordo com Mill, "as faculdades humanas da percepção, do julgamento, do sentimento discriminativo e mesmo da preferência moral só podem ser exercidas quando se faz uma escolha” (MILL, [1859], 2010, p. 117).

Ao desenvolvimento do indivíduo, para que suas potencialidades possam crescer por si, por conseguinte, é necessário fazer uso consciente e inteligente dos costumes, e a mesma liberdade deve ser guardada para que a conduta possa ser desviada dos padrões médios. Assim, na proporção do desenvolvimento de sua individualidade, cada pessoa se torna mais valiosa para si e, da mesma forma, para a coletividade. Seus impulsos são mais fortes, portadores de maior energia humana e se tornam mais equilibrados 
proporcionalmente ao uso da razão no juízo de suas opiniões e ações. O que pode ser reforçado com suas palavras pelo seguinte:

Não é reduzindo até a uniformidade tudo o que é individual em si, mas cultivando e impulsionando a individualidade, dentro dos limites impostos pelos direitos e interesses dos outros, que o ser humano se torna um nobre e belo objeto de contemplação; e como participam dos trabalhos o caráter de todos aqueles que o fazem, pelo mesmo processo a vida humana também se torna rica, diversificada e animada, fornecendo alimento mais abundante para pensamentos e sentimentos elevados, e reforçando o vínculo que liga cada indivíduo à raça, tornando infinitamente mais valioso pertencer a ela (MILL, [1859], 2010, p. 124).

Portanto, "tendo dito que a individualidade é a mesma coisa que desenvolvimento, e que é somente o cultivo da individualidade que produz, ou pode produzir, seres humanos bem desenvolvidos" (MILL, [1859], 2010, p. 125), há de se construir um convencimento na direção de sua utilidade, no valor da individualidade para o desenvolvimento geral de todos os homens, para o avanço humano nas mais diversas questões. Desse modo, esse é o quesito para que se reconheça que a originalidade e a genialidade, assim como outras características que permitem definir um indivíduo como desenvolvido, têm grande valia para os indivíduos ditos "não desenvolvidos".

Entre outras coisas, conforme suas palavras, são esses o "sal da terra", sem eles a experiência humana encontraria rapidamente a estagnação, principalmente porque não seria mais recorrente a descoberta das boas coisas e perderiam vida também aquelas que já foram descobertas.

Ora, segundo o autor, sendo os indivíduos desenvolvidos aqueles homens de propósito, os quais julgam os costumes e as opiniões (dominantes ou não) segundo sua própria razão, não se contentando facilmente em aceitar o que está dado, propondo conceber novas formas de vida e de experiência, de modo que possam ser reconhecidos frequentemente como geniais, ou pelo menos de grande originalidade, então é neles que se situam o verdadeiro valor para a direção da humanidade. Não de forma tirânica, mas através de uma liberdade que, não só fomente, mas torne imperativo que os homens busquem desafiar as opiniões correntes e propor novas concepções, sobretudo acerca das instituições políticas. 
Os mais capazes, os quais estejam à frente nesse quesito em cada processo, devem ser considerados mais aptos para exercer algum tipo de influência sobre os demais. Pois:

\begin{abstract}
A iniciativa de todas as coisas sábias e nobres vem e deve vir dos indivíduos; geralmente, pela primeira vez, de um único indivíduo. A honra e a glória do homem mediano é ser capaz de seguir essa iniciativa; pois ele pode responder internamente às coisas sábias e nobres e pode ser guiado por elas com os olhos abertos. Não estou admitindo aquele tipo de 'culto ao herói', que aplaude o homem forte de gênio que, pela força, se apodera do governo do mundo e faz com que ele o obedeça, a despeito de si próprio. [...] Todavia, parece que quando as opiniões de massas compostas tão-somente de homens medianos se convertem ou estão em vias de se converter na força dominante, então o contrapeso e a correção dessa tendência deverá ser a individualidade cada vez mais pronunciada daqueles que estão situados em uma reconhecida superioridade de pensamento (MILL, [1859], 2010, p. 129).
\end{abstract}

Nesse momento do texto, aparecem traços claros das relações que o autor concebe e que nos interessam particularmente. Como constatado, o problema de Mill com a maioria, com a massa, com a opinião pública, logo, em sua concepção, com a mediocridade, está nas diversas mazelas potenciais caso se tornem um poder dominante, bastando apenas para tanto que passem a ser algo a suprimir a espontaneidade, a excentricidade, a originalidade e a genialidade, por meio da condenação moral e que vão se agravando à medida que passem a ser objetos de penalidades formalmente prescritas.

Para ele, o problema é que há sempre uma tendência nessa direção, ou seja, de que a opinião pública, a massa, a mediocridade, tendencialmente venham a reger o mundo uma vez que o "espelho das opiniões" do homem médio geralmente é situado em seus semelhantes, tão medíocres quanto, implicando assim em governos medíocres.

Deve-se considerar, portanto, que a relevância da questão não está adstrita ao reconhecimento do mérito intrínseco da superioridade de caráter, de mentalidade, de intelectualidade ou de criatividade. Não é mera questão de honra ao mérito colocar os melhores homens à frente da condução dos negócios humanos, mas dos diversos prejuízos ou pelo menos da ausência de benefícios, quando ocorre o contrário. Analogamente, o ponto não está em proteger indivíduos potencialmente superiores da tirania da mediocridade, mas reconhecer seu valor para a coletividade; é o melhor para a maioria dos negócios humanos realmente importantes. 
É sobre essa base que, uma vez definido o critério para a determinação da esfera de liberdade individual, de forma negativa - isto é, a liberdade na medida em que ao indivíduo é permitido fazer tudo o que não afeta diretamente os demais -, o autor discute como e quando esse princípio deve ser aplicado concretamente e, além disso, quais situações devem ser consideras exceções ou peculiaridades. Neste texto, o mais importante é indagar como e até que ponto toda a reflexão situada no limítrofe entre indivíduo e governo pode ser considerada uma transposição dessa formulação da liberdade e seus desdobramentos.

\section{O governo representativo como transposição da liberdade}

Com base na leitura do ensaio Sobre a Liberdade, atendo-se a algumas nuances que poderiam moldar a concepção milliana sobre as instituições políticas, sobretudo o papel da representação democrática, serão examinados, a seguir, os principais elementos do texto Considerações sobre o Governo Representativo, a fim de buscar, conforme o interesse aqui exposto, identificar seus nexos discursivos.

\section{O progresso institucional como produto qualificado das opiniões e ações individuais}

Antes de conceber categoricamente a representação democrática como a forma de governo ideal, Mill estabelece algumas condições de sustentação das instituições políticas. Mais do que isso, propõe critérios para estabelecer uma forma de governo como melhor que outras.

De acordo com seus argumentos iniciais, qualquer que seja a forma de governo, esta é sempre mais próxima de uma escolha do que um dado da realidade histórico-social ${ }^{9}$. A concepção fundamental de Mill é a de que as instituições políticas são predominantemente obra dos homens e devem sua existência a vontade humana. Não só a criação, mas a evolução gradual das instituições depende da atenção e ação voluntárias dos homens, pois todos os seus mecanismos de mudança, de manutenção e de operação só têm forma e

\footnotetext{
${ }^{9}$ Essa posição é relativizada por Mill no texto, pois admite alguma interseção razoável entre duas teses opostas sobre a realidade institucional. Se por um lado, determinado conjunto institucional é influenciado por uma espécie de força da natureza, como um produto espontâneo da realidade histórica, por outro, pode ser moldado ao sabor das opiniões e convicções, e em sua opinião predominantemente o é.
} 
sentido a partir de suas mãos, ou seja, de sua participação ativa. Segundo o autor, a capacidade de melhorar as instituições é modulada pela capacidade e qualidade dos homens disponíveis.

A partir dessa noção, a possibilidade de realização do governo ideal implica em três condições, resumidamente: i) consentimento público; ii) vontade e capacidade de pronunciamento público; iii) vontade e capacidade de atender às exigências pelas quais o governo atinge seus objetivos. Para qualquer forma de governo ter sentido - e possa ser, portanto, preferível a outra - é preciso que essas três condições sejam atendidas. Por exemplo, no caso do governo representativo, ele diz:

\begin{abstract}
De mesmo, as instituições representativas são de pouco valor, e podem ser mero instrumento da tirania ou da intriga, quando a generalidade dos eleitores não está suficientemente interessada em seu próprio governo para dar-lhe seu voto, ou quando a maioria dos eleitores, quando votam, não o fazem segundo os interesses-do bem público, mas o fazem por dinheiro ou por indagação de pessoa influente, que por razões particulares pretendem favorecer. A eleição popular praticada dessa maneira, ao invés de ser uma garantia contra o mau governo, representa uma engrenagem adicional no seu mecanismo (MILL, [1862], 2006, p. 8).
\end{abstract}

Dessa forma, a incapacidade potencial em atender às exigências para um bom governo - a terceira das três condições -, que nesse exemplo é representada pela incapacidade ou desinteresse do povo de se comprometer com as eleições, faz com que o governo representativo deixe de ser uma forma adequada. Existem, portanto, diversas formas ideais de governo, as quais poderiam ser estabelecidas a priori a depender de como dado povo é capaz de atender àquelas três condições.

$\mathrm{Na}$ síntese de Mill sobre as formas de governo serem espontâneas ou deliberadas, portanto, a capacidade de escolha e a ação têm razoável primazia. Logo, apesar de fatores históricos facilitarem a realização das três condições, o autor argumenta que fatores ligados à história, cultura e costumes não devem ser tratados como condições necessárias à adoção desta ou daquela instituição. A potencial facilitação que os costumes oferecem à adequação a um dado arranjo institucional - ou seja, ao cumprimento de condições para uma dada institucionalidade - não deve sobrepujar a possibilidade de desenvolvimento de aptidões culturais por instituições melhores. 
Nas palavras de Mill, há que se "acender" no povo o desejo por instituições consideradas mais adequadas, pois "recomendar e defender uma instituição ou forma de governo específica, pondo em evidência suas vantagens, é uma das maneiras, frequentemente a única maneira possível de educar o espírito nacional que aprende assim não apenas a aceitar e a reivindicar, mas também a manejar a instituição.” (MILL, [1862], 2006, p. 10).

Acontece que uma dada característica social preestabelecida dificilmente poderia ser desconsiderada como força nas composições políticas. Não obstante, ainda que se considere determinado poder social, por exemplo, a capacidade ou força físicas, a propriedade e a inteligência, Mill acredita que só se manifestam enquanto um poder político quando passam a ser exercidos de forma ativa, o que nem sempre acontece.

Em sua concepção, o poder social geralmente representa pouco do poder político existente, pois pauta ativamente a esfera política apenas em pequenas parcelas. Para ele, a forma de poder político que mais pode desestabilizar relações de poder social é aquela baseada na capacidade de “propagação de convicções morais" (MILL, [1862], 2006, p. 12). Essa ideia pode ser bem ilustrada com a seguinte formulação:

Politicamente falando, uma grande parte do poder consiste na vontade. [...] a opinião em si é uma das maiores forças sociais ativas. Uma pessoa com uma crença política é um poder social igual a noventa e nove outras pessoas que possuem apenas interesses. Aqueles que conseguirem criar uma persuasão geral de que uma certa forma de governo, ou um fato social, de qualquer espécie, merece ser preferido, terão dado o passo mais importante que pode ser dado para arregimentar a seu lado os poderes da sociedade ([1862], 2006, p. 11).

Essa afirmação coaduna perfeitamente com a liberdade de pensamento e discussão encontrada no manuscrito Sobre a Liberdade; sendo ela uma das principais características do "lugar apropriado da liberdade", podemos afirmar que é sobre ela que Mill apoia a necessidade de um governo pela representação. Ou seja, condicionado à uma certa liberdade de discussão, o poder de propagação de convicções determina em grande parte o sentido resultante da disputa pelo poder social, mas para tal é também necessário que a sociedade esteja apta à formação de opiniões, bem como à propagação das convicções dela resultantes. 
Esse é um ponto importante de ligação entre as duas obras que permite identificar o progresso institucional como uma forma potencial de expressão da liberdade. Em outras palavras, o progresso institucional é tratado como uma espécie de produto qualificado das opiniões e ações individuais. É importante também frisar, recorrendo novamente às suas palavras, que "o simples poder físico e econômico está longe de ser o poder social como um todo"; pois para o autor, destarte a civilização seja capaz de ser governada pela opinião, essa deve ser uma das características primordiais para o estabelecimento das condições para o convívio e progresso humanos, especialmente na escolha da forma de governo ideal.

Sendo assim, a capacidade de julgamento e convencimento dos indivíduos deve ser confiada não apenas à boa condução e administração dos assuntos coletivos, mas também o aprimoramento de suas formas, isso porque são essas capacidades as que apresentam o melhor potencial para tanto.

\section{A representação da individualidade como desenvolvimento}

A partir da constatação exposta anteriormente, antes de avançar até a concepção de que a melhor forma de governo se dá pela representação, vale a pena se ater à concessão feita por Mill - em suas palavras, "em benefício da discussão" -, em torno da qual alguns elementos de interesse deste trabalho são esboçados. Supondo possível existir um "bom déspota" - hipoteticamente, um indivíduo eminente e capaz de controlar todas as suas ações, da formulação até a execução, ou escolher os melhores homens para tanto, todos de sua confiança -,Mill discute quais as possibilidades de estabelecimento de um governo virtuoso pelo despotismo.

Fosse tal feito possível, abrindo mão ainda de diversas outras contradições que tornariam sua plausibilidade inconsistente - lembrando também que para Mill a única exceção que torna o despotismo aceitável seria uma espécie de totalitarismo transitivo, visando especificamente conduzir às sociedades para um estágio de civilização mais avançado, capacitando-a, logo em seguida, a usufruir dos benefícios da liberdade ${ }^{10}$-, ainda assim, no governo

\footnotetext{
10 Essa questão é bem conhecida na literatura, pode oferecer algum benefício à sua compreensão a seguinte citação literal: "Mal por mal, um bom despotismo, em um país com uma civilização totalmente avançada, é mais prejudicial do que um mau despotismo; uma vez que reduz e enfraquece os pensamentos, os sentimentos e as energias do povo." (MILL,
} 
pelo poder soberano individual ou de poucos, não seria possível cumprir o principal papel de qualquer modalidade de governo, qual seja, o "aperfeiçoamento do próprio povo". Isso por que, em suas palavras, "sempre que a esfera de ação dos seres humanos é artificialmente restringida, seus sentimentos são limitados e diminuídos na mesma proporção” (MILL, [1862], 2006, p. 50).

Desse modo, mesmo que a submissão a um senhor bom e sábio pudesse trazer algum benefício na administração das coisas públicas, prestaria um grande desserviço ao discernimento e ao desenvolvimento das faculdades práticas, intelectuais, mentais e morais. Diante disso, Mill estabelece dois ramos pelos quais transitar para que a argumentação pela representação adquira o devido sentido. O primeiro diz respeito à boa administração das coisas públicas, as quais um suposto bom despotismo seria capaz de realizar, mas não com a mesma capacidade de um governo pela representação. O segundo ramo se preocupa com o desenvolvimento do conjunto mais proeminente de capacidades e qualidades humanas, que poderiam ser retoricamente definido como excelência.

De acordo com Mill:

A forma de governo idealmente melhor, é praticamente desnecessário dizer, não significa aquela que é praticável ou elegível em todos os estados de civilização, mas aquela que, nas circunstâncias em que é praticável ou elegível, traz uma grande quantidade de consequências benéficas, imediatas e futuras. Um governo totalmente popular é a única constituição que pode reivindicar esta característica. Ela é superior em ambos os departamentos em que se divide a excelência de uma boa constituição política. Além de ser mais favorável para proporcionar um bom governo, também promove uma forma melhor e mais elevada de caráter nacional do que qualquer outra constituição (MILL, [1862], 2006, p. 54).

Portanto, o primeiro ramo está centrado nas consequências imediatas, para as quais somente no governo com ampla representação é possível encontrar uma defesa dos interesses dos indivíduos, pois é possível a todos não só sustentar seus interesses, mas também encontrar motivações para que assim o façam. O autor recai então no pressuposto antropológico do traço predominantemente egoísta do caráter dos homens, que "preferem a si

[1862], 2006, p. 54); pois que o bom despotismo, para Mill, é uma quimera, e se existir um despotismo melhor que outro, na verdade, o primeiro "prepara" o povo para o segundo, ou seja, aniquilando o caráter e tudo aquilo mais que faz dum povo mentalmente ativo. 
mesmos ao invés dos outros, preferem os que lhe são mais próximos e não mais distantes" (MILL, [1862], 2006, p. 55).

A peculiaridade, no entanto, dessa noção no pensamento milliano se dá pelo reconhecimento do predomínio de tal característica, ao passo que defende ser desejável que os homens desenvolvam a capacidade de se comportar de maneira oposta, e tão logo o fizessem, seria, na verdade, o comunismo a única forma defensável de organização social. Nas palavras de Mill não há que se falar em doutrinas de egoísmo universal, pois “o comunismo seria, mesmo agora, praticável entre a elite da humanidade, podendo também ser praticável pelo restante" (MILL, [1862], 2006, p. 55).

Mas é no segundo ramo que se dá a defesa do governo pela representação, a qual interessa neste estudo especialmente, pois isso favorece, segundo Mill, o caráter ativo dos homens; neste tipo de governo se encontram as motivações para que os indivíduos se desenvolvam e busquem exercer sua influência política utilizando o que têm de melhor.

Segundo o autor, toda a superioridade intelectual é fruto do esforço ativo e só em um governo onde é assegurada ao indivíduo essa possibilidade é que tal característica é desenvolvida. Em suas palavras "O caráter que traz melhorias à vida humana é aquele que luta contra os poderes e tendências naturais, não aquele que cede a eles" (MILL, [1862], 2006, p. 34), por isso, ser deixado de fora das decisões do governo é um grande desencorajamento aos indivíduos.

Em sua concepção a única forma de governo que permite a participação de todos é a representação, tendo em vista a simples observação da inviabilidade de uma democracia direta em uma sociedade maior que um vilarejo $^{11}$. Logo, esses são os principais termos em que se dá a argumentação de Mill de que a forma de governo ideal é o governo representativo.

\footnotetext{
11 Tendo em vista a aparente insuficiência desse argumento, que poderia conduzir a conclusões equivocadas, Araújo (2006) oferece um entendimento abrangente da questão com os seguintes dizeres: "Seguindo a terminologia dos economistas clássicos, Mill distingue 'trabalho produtivo' e 'trabalho improdutivo' [...]. Trata-se de encontrar a melhor combinação dos dois: a maior disponibilidade de trabalho produtivo com o menor uso de trabalho improdutivo. Mas a democracia direta é um governo em que todos se envolvem com as tarefas da administração pública - trabalho improdutivo, o que requer muito tempo, em prejuízo do trabalho produtivo. Conclusão: a separação entre governantes e governados está mais de acordo com a utilidade geral, pois neste caso a maioria se dedica ao trabalho produtivo enquanto uma minoria se ocupa full time com a administração." (ARAUJO, 2006, p. 284).
} 


\section{Outras "Considerações sobre o Governo Representativo"}

Sobre as condições necessárias para a existência do governo pela representação, destacam-se três: (1) quais são as condições de inaplicabilidade do governo representativo; (2) quais são as funções peculiares do corpo representativo; (3) a extensão do sufrágio.

$\mathrm{Na}$ primeira delas, ao discutir sob que condições sociais o governo representativo se torna inaplicável (1), é retomada, de alguma forma, a questão - também presente em Sobre a Liberdade e em diversos outros escritos sobre as sociedades consideradas atrasadas e também aquelas que, tendo já atingido alguma maturidade, são ambas impropriamente adaptáveis às três condições necessárias ao bom funcionamento do governo representativo.

No caso das sociedades consideradas primitivas (ou "atrasadas"), Mill considera inapropriada a existência de uma assembleia representativa, pois retrataria apenas a desobediência do povo e não seria possível contornar a incapacidade deste de se submeter a um superior comum. Povos que, ao contrário, fossem passivos demais também não estariam em condições de se desenvolver sob o julgo de si mesmos, prefeririam sempre serem representados pela própria tirania, ao passo que povos preparados para a liberdade, mas incapazes de se juntar com base em interesses comuns, também são exemplos de onde a monarquia supera melhor os obstáculos civilizatórios.

Aqui interessa também sua concepção sobre as funções peculiares do corpo representativo (2), porque para Mill as opiniões devem ser idealmente adstritas àquela parcela do aparato público, onde o indivíduo e suas características de diferenciação não podem ser superiores à coletividade em deliberação, ou seja, principalmente naquelas atividades legislativas onde se depende de uma pluralidade de opiniões e das discussões dela concomitantes. Segundo suas palavras, 


\begin{abstract}
Até mesmo um corpo escolhido, composto de poucos membros, e estes especialmente familiarizados com o trabalho a ser executado, será sempre um instrumento inferior a algum indivíduo que possa encontrar-se entre eles e, que poderia aprimorar o caráter se fosse eleito como chefe e todos os outros colocados como subordinados. A deliberação é o que um corpo pode fazer melhor do que qualquer outro indivíduo. Quando é necessário ou importante obter manifestações e considerações sobre muitas opiniões divergentes, um corpo deliberativo tornase indispensável (MILL, [1862], 2006, p. 81).
\end{abstract}

De forma alguma esgotando os capítulos do livro, tampouco a discussão em torno das ideias de Mill sobre o assunto em tela, cabe por último comentar aspectos de sua concepção sobre a extensão do sufrágio (3). De antemão, Mill estabelece algumas condições positivas que devem ser observadas a priori para tratar os indivíduos como inaptos para o exercício do sufrágio, tais como analfabetos, pessoas que recebem ajuda financeira do governo, insolventes fiscais, empreendedores em situação de falência etc., em suma, todos aqueles que positivamente não deverão disputar o destino da sociedade por não se encontrarem em pleno cumprimento de seus deveres.

Tendo então reconhecido um dos benefícios mais preeminentes do governo pela representação, o de prestar um serviço à elevação das qualidades individuais, sobretudo às camadas que mais precisam de aprimoramento, mesmo estando neutralizados alguns males a que possa estar exposta a democracia, Mill qualifica a necessidade de contornar algumas distorções que podem tornar o governo menos eficaz na promoção do aprimoramento ou, no limite, levar a democracia à degeneração. Conquanto, em princípio, as diversas opiniões devam ser ouvidas para o benefício da pluralidade, devem fazê-lo pelo seu valor intrínseco, e não mais do que isso, o qual é dado pelas capacidades individuais que geralmente fazem a opinião ser mais racional e mais qualificada, distanciando-se da mera vontade ou interesse; em suas palavras "a única coisa que justifica o fato de a opinião de uma pessoa valer mais do que as outras é a superioridade mental individual" (MILL, [1862], 2006, p. 93).

Para o autor, algum critério que represente essa proposição deve ser preferido em detrimento dos que representem somente vantagens pecuniárias, ainda que estes sejam algo admissível transitoriamente. Deve ser descartado de imediato, por exemplo, se existir algum meio de aferir o escalonamento dos méritos individuais pela natureza das ocupações na divisão do trabalho, pois, "um empregador é geralmente mais inteligente que um trabalhador, uma vez 
que deve trabalhar com a cabeça, e não apenas com as mãos; um mestre de obras é geralmente mais inteligente que um obreiro comum" (MILL, [1862], 2006, p. 93).

No entanto, qualquer que seja a melhor forma de ponderação da capacidade de exercício de poder político, ela deve privilegiar os indivíduos mentalmente mais bem-dotados, entretanto, nunca fazendo com que os privilegiados prevaleçam sobre o resto da comunidade. Guardada essa perspectiva, a forma mais plausível seria conferir à educação formal o critério de contrabalanço do peso numericamente superior das classes menos instruídas. O objetivo seria sempre o de potencializar a capacidade dessa forma de governo, qual seja, a disputa em torno da representação, pois engendra um enfrentamento entre as diversas classes que favorece seu desenvolvimento mental, sendo a conquista do poder dada sempre por meio da razão, e nunca em detrimento dela.

Por fim, Mill enuncia diversas razões para acreditar que a defesa do direito ao voto pelas mulheres é, senão, mais um fator a concorrer para fazer do sufrágio, e do governo pela representação, a forma ideal para a promoção do desenvolvimento das capacidades individuais.

\section{Liberdade, progresso institucional, representação e outras conclusões}

Diante do exposto, cabe observar que a leitura do Ensaio sobre a Liberdade com o propósito estabelecido permite afirmar que sua defesa eloquente da liberdade pode ser considerada a pedra angular para interpretar algumas das principais ideias do autor. É sobre os principais argumentos de sua concepção particular de liberdade que é concebida a melhor forma para a condução dos interesses que ultrapassam o domínio do indivíduo.

Em Mill, o progresso institucional pode ser compreendido como uma espécie de produto qualificado das opiniões e ações individuais. $\mathrm{O}$ autor enxerga na capacidade de formulação e propagação de opiniões, senão toda, pelo menos a maior fonte de poder político nas sociedades consideradas civilizadas.

A partir disso, o melhor governo é aquele em que melhor se aproveitem as possibilidades de desenvolvimento das faculdades humanas. $\mathrm{O}$ "governar" ideal deve, pois, potencializar as aptidões mentais e intelectuais dos 
indivíduos, bem como seu aprimoramento moral. Em suma, a supremacia do desenvolvimento da individualidade deve estar plasmada nas instituições governamentais, que devem transportar o melhor da esfera individual para a esfera pública.

Para isso, há de se estabelecer uma espécie de escala de mérito das opiniões dos indivíduos, revelando-se o caráter aristocrático das ideias políticas do autor, as quais são típicas da etapa inicial de alargamento das fronteiras democráticas inglesas, em que os representantes naturais de cada camada social deveriam ser idealmente os seus superiores sociais. Entretanto, Mill relativiza essa posição ao advogar que é necessário encontrar uma espécie de fino ajuste para não privar a sociedade dos benefícios oriundos da excelência individual das classes superiores nem sufocar demais as classes inferiores, mantendo acesa a disputa em torno do poder dentro da sociedade.

Tais características permitem aprender mais sobre a origem dos valores que ainda predominam em muitos setores das sociedades atualmente. Vale lembrar que, no período em que foram publicadas, a Inglaterra exercia hegemonia considerável, tanto no campo das riquezas quanto no das ideias, quadro que mudou bastante nos séculos seguintes. Não se mudou, no entanto, a democracia e a excelência individual como um par discursivo recorrentemente atrelado a certo ideal de desenvolvimento humano.

\section{Referências}

ARAÚJO, Cícero. Bentham, o Utilitarismo e a Filosofia Política Moderna. In: Boron, Atilio A. Filosofia política moderna: de Hobbes a Marx. São Paulo: USP, 2006.

BOBBIO, Norberto. O Futuro de Democracia. São Paulo: Paz e Terra, 2000.

DENIS, Henri. História do Pensamento Econômico. Lisboa: Livros Horizonte, 1978.

GUTMANN, Amy. A desarmonia da democracia. Lua Nova, n.36, pp. 5-37, 1995.

HEILBRONER, Robert. A História do Pensamento Econômico. São Paulo: Nova Cultural, 1996.

HEYDT, Colin. The Internet Encyclopedia of Philosophy. Disponível em: <http://www.iep.utm.edu/>. Acesso em: 13 out. 2019. 
HEYDT, Colin. Mill, Life as Art, and Problems of Self-Description in a Industrial Age. In: EGGLESTON, BEN; MILLER, DALE E.; WEINSTEIN, DAVID. John Stuart Mill and the Art of Life. Nova York: Oxford University Press, 2011.

KAHAN, Alan. Aristocratic liberalism: the social and political thought of Jacob Burckhardt, John Stuart Mill and Alexis de Tocqueviile. New York: Oxford University Press: 1992.

KERSTENETZKY, Celia Lessa. Sobre associativismo, desigualdades e democracia. Revista Brasileira de Ciências Sociais, vol.18, n.53, pp. 131142, 2003.

LEVKOVYCH, Oksana. Aspects of Colonialism in John Stuart Mill's: On Liberty (1859) and Considerations on Representative Government (1861). In: FERREIRA, José Carlos Viana; MALAFAIA, Teresa de Ataide. The British Empire: ideology, perspectives, perceptions. Lisboa: Centro de Estudos Anglísticos da Universidade de Lisboa, 2010.

MACPHERSON, C.B. A democracia liberal - Origens e Evolução. Rio de Janeiro: Zahar Editores, 1978.

MATTOS, Laura Valadão. A posição de J.S.Mill em relação ao Estado: os casos das sociedades 'avançadas' e das sociedades 'atrasadas'. Economia e Sociedade, Campinas, Unicamp, v. 17, p. 135-155, 2008.

MILL, John Stuart. [1848]. Princípios de Economia. São Paulo: Nova Cultural, 1996.

Paulo: Hedra, 2010.

[1859]. Sobre a Liberdade. Tradução: Ari R. Tank Brito. São [1961] A Liberdade - O Utilitarismo. São Paulo: Martins Fontes, 2000.

[1862]. Considerações sobre o governo representativo. São Paulo: Escala, 2006.

[1873]. The Collected Works of John Stuart Mill Autobiography and Literary Essays. Ed. John M. Robson and Jack Stillinger, introduction by Lord Robbin. Toronto: University of Toronto Press, 1981. v.1.

OFFE, Claus, 1984. Problemas Estruturais do Estado Capitalista. Rio de Janeiro: Tempo Brasileiro.

PAULA, Marcio Gimenez de. O Estado e o Indivíduo: o conceito de Liberdade em John Stuart Mill. Polymatheia - Revista de Filosofia, Fortaleza, Vol. III, n. 3, 2007, p. 73-84. 
ROLL, Eric. História das doutrinas econômicas. São Paulo: Cia Editora Nacional, 1972.

SARTORI, Giovanni. [1987]. A Teoria da Democracia Revisitada - O debate contemporâneo. São Paulo: Ática. v. 1.

SILVA, Antonio Ozaí da. Notas sobre a liberdade e a tirania da maioria em Stuart Mill. Revista Espaço Acadêmico, No 101, 2009.

TOCQUEVILLE, Alexis de. [1835]. A Democracia na América. Tradução: Eduardo Brandão. São Paulo: Martins Fontes, 2005.

WEFFORT, F. C. (Org.). Os Clássicos da Política. São Paulo: Ática, 1989.

WOOD, Ellen Meiksins, 2003. Democracia contra capitalismo: a renovação do materialismo histórico. São Paulo: Boitempo. 